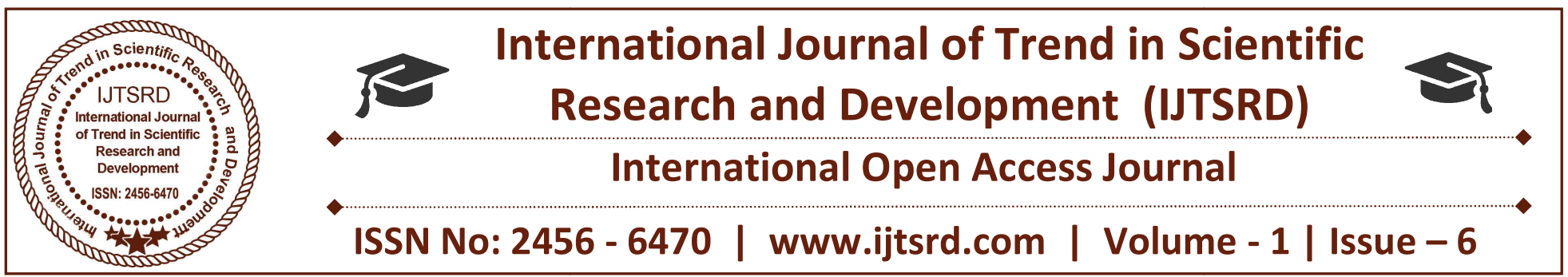

\title{
Organisational Violence
}

\author{
K. M. Srisruthi \\ BBA. LLB.(Hons.), Saveetha School of Law, \\ Chennai, Tamil Nadu
}

\section{ABSTRACT}

This paper talks about the major impact that work pressure has on people and the organisations. It focuses on the negative impact it has on the both. It also tells us the types of organisational violence that occurs and their most probable reasons. It also focuses on the point that the organisational violence can be both physical and verbal, their individual impact. It has also addressed the fact that how common organisational violence has become. It also us the reasons why organisational violence occurs. It also shows statistical rates of homicide due to organisational violence.

\section{INTRODUCTION}

Organisational violence has become a common component in the society now, as everyone is running behind corporate jobs. Organisational violence has become inevitable evil in our society. Organisational violence occurs when an organisation avoids proper/ethical decision- making by continually narrowing choices in turn making organisations and people working in these organisations suffer. In other words we can tell that organisational violence is a main cause of stress in the life of people who are working. An example of organisational violence is as follows: When an organisation asks an employee to do office related work when the employee is on leave be it coming to office or working from home it is organisational violence. This organisational violence could lead to the employee not being able to work to his or her full potential due to added pressure.

\section{ISSUES}

The major reasons due to which organisational violence occurs due to the lack of the following:

$>$ The ability of people and organisations to form bonds to form collaborations and to maintain these collaborations.

$>$ Being open to everyone's idea or ideals in your team or group rather just following one person's suggestion.

$>$ Balancing with the individuality and work ethics performance of the team

> Peacefully resolving issues related control, power and authority

And Organisational performance should go beyond the completion of a project, it must also take into account the health of the person and maintain an even balance between both.

One should understand that work related violence does not affect the employee alone but it also affects the organisation. In short we can understand that it has a negative impact on both.

Assessing the true extent of organisational violence is difficult as research and statistical studies often use different criteria to what constitutes as organisational violence, who is to be involved and where the incident should take place for it to be considered as organisational violence. Some people focus on attempted or actual physical assault while others define it as any form of harm intended harm coworkers of the organisation. Hence we can come to an understanding that organisational violence is any form 
of physical or verba abuse which is done due to work related issues. Organisational violence can be of 3 types;

1. In case of robberies, where the attacker has no legitimate relation with the victim,

2. In cases where the person who attacks is a receiver of services or object from the victim

3. This case involves attack of on employee on the other i.e it generally consists members of the organisation.

It has been shown in studies that in US in the year 2001, 639 work related homicides have occurred. It was found that homicide was the 3rd leading cause in occupational fatality overall and 2 nd in women. It is shown that these work related assaults have caused injuries which were both fatal and non-fatal and has also been a cause of homicide. It is found that in particular hospital and health care workers have found to be at high risk of organisational violence in particular the non fatal violence. But we should understand that violence is it fatal or non-fatal has a disturbing mental effect on the victim. Making the victim more susceptible stress and depression. Hence making organisational violence an active cause of depression and stress.

Organisational violence need not be physical assault which is fatal or non-fatal; it can also be of the verbal form. Verbal abuse is more common in organisations than one can imagine.

These days many people experience verbal abuse. One can say that verbal abuse will greatly affect the individual as it lowers the self esteem of person, hence reducing the individual productivity of the person. These forms of organisational violence has been major factor in affecting the health of working individuals, as high levels of stress are the major causes of various diseases in individuals. Organisational violence has become so common that it has become an integral part of every organisation. It is noticed that organisational violence in physical form is very commonly observed between the employees and client, as one is obligated to be polite to their clients. So one can tell that organisational violence which is physical is more common in service related fields were one has to communicate with their client. Whereas verbal abuse is more common inside the organisation from the boss to employee, etc.
The impact of organisational violence is huge on and individual or the organisation. It causes health problems. Affects the performance of the company, affects the productivity of type employees. Hence having a negative impact on both the individual and organisation as mentioned above

\section{CONCLUSION}

From this we are able to understand that organisational violence has a major impact on every employee or the organisation. Hence forming a major hindrance for the organisation. Organisational violence should be abolished as an organisation can reach it's complete utility only when the employee of the organisation does not feel inhibited or barricaded. Hence a proper bond with the employees will help in the proper functioning. If there is no organisational violence the employee will be able to work to their full potential. Hence one should bring in regulations inside the organisations that make the employee feel safe in the organisation. The feeling safety inside the organisation is very important for the individual to work well. I would like to conclude by telling that reduction in organisation violence will have a great amount of positive impact on the economy and the country.

\section{REFERENCES}

1) S G Gerberich, $T$ R Church, $P$ M McGovern, H E Hansen, N M Nachreiner, M S Geisser, A D Ryan, S J Mongin, G D Watt. An epidemiological study of the magnitude and consequences of work related violence: the Minnesota Nurses' Study. Occup Environ Med 2004;61:495-503. doi: 10.1136/oem.2003.007294

2) Speedy S. Workplace violence: the dark side of organisational life.

3) Wieclaw J, Agerbo E, Mortensen PB, et al Work related violence and threats and the risk of depression and stress disorders Journal of Epidemiology \& Community Health 2006;60:771775.

4) Phil Leather, Tom Cox et al. Work related violence - Assessment and intervention. 